\title{
Design e complexidade: aplicação de um jogo colaborativo a fim de idear soluções para os problemas da mineração
}

Design and complexity: application of a collaborative game to devise solutions to the problems of mining

BARBALHO, Thalita; Mestranda; Universidade do Estado de Minas Gerais

barbalho.thalita@gmail.com

LACERDA, Ana Carolina; Mestre; Universidade do Estado de Minas Gerais

anacarol_lacerda@hotmail.com

GUIMARÃES, Letícia; Mestre; Universidade do Estado de Minas Gerais

hg.leticia@gmail.com

ENGLER, Rita de Castro; ph.D.; Universidade do Estado de Minas Gerais

rcengler@uol.com.br

\section{Resumo}

O cenário do setor de mineração em Minas Gerais, Brasil, apresenta a necessidade de reflexão sobre as suas consequências, tanto em relação aos impactos ambientais, como em relação às comunidades em seu entorno. Essa é uma difícil equação, devido à alta complexidade dos problemas e ao grande número de pessoas e interesses envolvidos. Este estudo apresenta o designer como possível agente na busca pela elucidação dessas questões, cuja resolução é social, econômica e ambientalmente complicada. Objetiva-se entender como o design, por meio dos seus processos e ferramentas, pode auxiliar a projetar para a complexidade. Após revisão bibliográfica, segue-se um estudo de caso da aplicação do jogo, que contribui para a solução de questões complexas como a mineração usando da ludicidade e do fomento à reflexão. Os resultados mostram que o mesmo pode ser utilizado em processos de codesign para gerar resultados em contextos cada vez mais complexos.

Palavras-Chave: design; problemas complexos; ferramentas do design; mineração.

\section{Abstract}

The mining scenario in Minas Gerais, Brazil, presents the need for reflection on its consequences, both in relation to environmental impacts, and the surrounding communities. This is a difficult equation because of the high complexity of the problems and the large number of people and interests involved. This study presents the designer as a possible agent in the search for the elucidation of these issues, with socially, economically and environmentally complicated resolutions. It aims to understand how design, through its processes and tools, can help design for complexity. After a bibliographical review, a case study of the application of the game follows, which, using playfulness and encouraging reflection, contributes to the solution of complex questions such as mining. The results show that it can be used in codesign processes to generate results in increasingly complex contexts.

Keywords: design; complex issues; design tools; mining. 


\section{Introdução}

Conforme entrevista concedida por Arthur Maia, presidente da Associação Mineira dos Municípios Mineradores de Minas Gerais (AMIG), entre 2017 e 2019, a mineração entrará ainda mais em crise em Minas Gerais, devido ao incidente do rompimento da barragem de Mariana/MG, associado à instalação do maior projeto de minério de ferro no Pará, chamado de S11D. Nesse sentido, coloca-se em pauta a urgência de se reduzir a dependência econômica e social da mineração, já que o produto explorado é finito, e o que ficará para as comunidades afetadas são, na maioria das vezes, apenas o buraco e os resíduos. Mas o design pode apresentar-se como agente que busca novas vocações para as comunidades impactadas e dependentes das grandes empresas.

Percebe-se que o contexto atual conta com as tecnologias informatizadas como forma de viabilização para mais trocas de ideias, capacidades e competências, tornando o cenário em que se vive fluido (BRANZI, s.d. apud MORAES,2010), dinâmico (BAUMAN, apud MORAES, 2010) e complexo (MORAES, 2010). Devido a esse dinamismo, não existe um caminho certo para solução de problemas perversos, também conhecidos pelo termo "wicked problems", como os impactos da mineração. A expressão "wicked problems" diz respeito a problemas instáveis que têm soluções turvas e cuja resolução é social, econômica e ambientalmente complexa. Os mesmos não dispõem de solução definitiva, sendo suas proposições qualificadas como boas ou ruins, e não verdadeiras ou falsas (RITTEL; WEBER, 1973).

As dificuldades e obscuridades desses problemas remetem ao fato de que esses desafios não são simples de ser resolvidos apenas por uma entidade. Dessa forma, compreende-se que Redes de design devem ser criadas entre indivíduos, empresas, organizações com ou sem fins lucrativos e instituições locais e globais, utilizando da criatividade e empreendedorismo para obter alguns valores compartilhados, de forma a gerir e solucionar esses problemas, que não devem ser entendidos apenas como responsabilidade dos atores políticos (DESIS, apud MORAES, 2010). 0 designer, ao interagir com esses diversos protagonistas da rede, pode viabilizar a convergência de ideias e soluções em direção à sustentabilidade de forma efetiva, ao utilizar seus conhecimentos específicos, estratégias e ferramentas.

Ele é, então, o centro e mediador desses processos, devido ao seu saber multidisciplinar, à sua forma de interpretar os processos e de entender as demandas dos usuários e, principalmente, pelo fato de, por meio de suas habilidades, criar ou modificar valores (CELASCHI, s.d. apud MORAES, 2010). Conforme Moraes (2010, p.65), o design, devido ao seu caráter holístico, transversal e flexível, é uma possível ferramenta para o entendimento da realidade contemporânea.

A revisão bibliográfica deste trabalho se constitui das temáticas da mudança do pensamento mecanicista para o pensamento complexo; discussões com relação à definição de complexidade; a problematização e complexidade da mineração no estado de Minas Gerais; e o papel do design nesse contexto de complexidade, buscando autores que sejam referência em estudos acadêmicos. Utiliza-se da metodologia de pesquisa-ação como forma de ligar prática e teoria.

Para exemplificar a potencialidade do design nesse campo de pesquisa, um jogo foi criado como forma de instigar o desenvolvimento de novas soluções dentro da problemática da mineração no estado de Minas Gerais, tendo sido aplicado na turma de pós-graduação da Escola 
de Design da Universidade do Estado de Minas Gerais, e seu resultado analisado criticamente como forma de averiguar o papel do designer na criação da ferramenta e na gestão da proposta.

\section{Do pensamento mecanicista ao pensamento complexo}

Desde o século XVII, o pensamento mecanicista tem sido dominante para o entendimento da natureza, da sociedade e das organizações. O racionalismo científico ou pensamento mecanicista buscava trazer o verdadeiro conhecimento para superar as incertezas da Idade Média e ficou caracterizado pela crença na ciência, além da razão.

Esse período também ficou conhecido como modernidade, que começou no lluminismo e se desenvolve até, aproximadamente, a metade do século XX, e foram, principalmente, as leis de Newton que marcaram e legitimaram o mecanicismo: linearidade, monocausalidade, determinismo, reducionismo e imediatismo são os pilares desse pensamento.

Segundo Torres (2009), o pensamento mecanicista afetou profundamente todas as áreas de conhecimento, principalmente após o surgimento da filosofia positivista - que teve início na França no começo do século XIX e defendia a ideia de que o conhecimento científico era a única forma de conhecimento verdadeiro - e o avanço tecnológico que a Revolução Industrial proporcionou. Torres (2009) explica que a objetividade da ciência e da tecnologia afastou, em muitos momentos, o pensamento em relação a critérios éticos e morais.

Torres (2009) explica que, no final dos anos 1970, com a revolução econômica apoiada na Tecnologia da Informação, começou a se delinear uma nova versão para a visão mecanicista de mundo. Além do capital tangível - eletrodomésticos, carros, móveis -, passou a ser considerada uma forma intangível de capital, a informação.

A ruptura do pensamento mecânico - baseado na linearidade e separado pelo muro de que apenas a comprovação científica tinha valor - para uma visão complexa e orgânica é a marca da pós-modernidade. Para Cardoso (2008), o período tem como característica o pluralismo, e nesse momento já não existia a pretensão de encontrar uma única forma exata de fazer as coisas, uma única solução que resolvesse todos os problemas, uma única narrativa que amarrasse todas as pontas.

Para Torres (2009), na visão complexa de mundo, a realidade é, essencialmente, definida pelos relacionamentos e pelos processos. Cada pessoa que está relacionada afeta e é afetada pelas ações e pelas ideias de todos os demais. O ser humano tem uma realidade biológica e cultural que não deve ser dividida.

Para tanto, o panorama percebido é a adaptação dos sistemas complexos pelos usuários, e assim os designers, nesse quadro de inovação colaborativa, estão se recriando para atuar como formadores da mudança entre os grupos de pessoas (THACKARA, 2005).

[...] a um primeiro olhar, a complexidade é um tecido (complexus: o que é tecido junto) de constituintes heterogêneos inseparavelmente associados: ela coloca o paradoxo do uno e do múltiplo. Num segundo momento, a complexidade é efetivamente o tecido de acontecimentos, ações, interações, retroações, determinações, acasos, que constituem nosso mundo fenomênico [...] (MORIN, 2006).

O arquiteto da complexidade, Morin (2006), recomenda a transdisciplinaridade e a religação dos saberes. Assim, frisa-se a imprescindibilidade de se ultrapassarem as barreiras entre disciplinas, a diversidade entre os sujeitos e objetos possibilitando a criação de conexões, fazendo 
da sala de aula uma ocasião favorável para dar início a processos de mudança de mentalidade (GUIMARÃES, 2018).

\section{3. $O$ que é complexidade}

Segundo Morin (2012), o termo "complexidade" surgiu na ciência, no século XX, com a descoberta da microfísica. De acordo com Torres (2009), as principais descobertas da ciência que contribuíram para a construção do pensamento foram: a do átomo, a de que, no interior dos átomos, existe muito mais espaço vazio do que matéria e a descoberta e decodificação do DNA.

Uma possível resposta é que o "complexo" é aquilo que está além da compreensão. (VASSÃO, 2010). Ainda outro entendimento da palavra "complexo" é aquilo que não pode ser disposto, apresentado, compreendido como algo simples, que não pode ser decomposto em pedaços menores e, portanto, mais simples, que não pode ser "reduzido". Ou seja, algo que é, por natureza, pelas suas própria características, "irredutível” (VASSÃO, 2010).

Para Cardoso (2012), a complexidade é um sistema composto de muitos elementos, camadas e estruturas, cujas inter-relações condicionam a uma redefinição contínua do funcionamento do todo. Algo como uma metrópole, que é constituída por diversos sistemas interligados, incontáveis elementos, numa relação intrincada de vaivém, sobe e desce, criação e destruição contínuos, sem que se saiba onde ela começa ou termina, e sem que ela venha a se extinguir nunca.

Morin (2012) enfatiza que a complexidade não compreende apenas quantidades, ela também compreende as interações, que desafiam as possibilidades de cálculo: ela abrange as incertezas, indeterminações, fenômenos aleatórios. A complexidade, num certo sentido, sempre tem relação com o acaso.

A visão complexa tende a considerar o todo, diferente do modelo de pensamento que foi construído ao longo da história ocidental. Morin (2012) explica que considera a existência de uma realidade econômica de um lado, uma realidade psicológica de outro, uma realidade demográfica de outro etc. Acredita-se que essas categorias sejam a realidade, mas esquece-se de que, no econômico, por exemplo, há as necessidades e os desejos humanos.

Da mesma forma, a mineração tem múltiplos fatores complexos relacionados que a especificam. Suas consequências e benefícios gerados a uma comunidade são vastos e precisam ser considerados ao pensar soluções para os pontos negativos gerados pela mesma.

\section{A mineração no estado de Minas Gerais}

De acordo com Haddad (2015), dentro do cenário atual da economia nacional, a mineração representa cerca de $5 \%$ do PIB brasileiro e $8 \%$ do PIB de Minas Gerais, além de ser o elo articulador de setores-chave dessa economia, como a siderurgia, que tem a capacidade de potencializar e expandir a geração de renda, empregos, tributos e excedentes exportáveis no país. Ainda segundo o autor, os benefícios socioeconômicos gerados em quase todos os municípios menos desenvolvidos do país onde está localizado um grande projeto de investimento de mineração e/ou siderurgia são muito expressivos: ocorre uma modernização na infraestrutura da cidade (econômica e social), o salário médio chega a ser elevado em cinco vezes, a arrecadação tributária do município tende a ser multiplicada por 10 e o mercado de trabalho se dinamiza e se diversifica. Atrelado ao desenvolvimento, toda implantação de um grande empreendimento traz 
também impactos ambientais e sociais, entendidos como problemas complexos, já que não têm uma solução única, eficaz e definitiva.

Em 05 de novembro de 2015, ocorreu o acidente de maior impacto da mineração brasileira, no município de Mariana, em Minas Gerais. O rompimento da barragem do Fundão, da mineradora Samarco, no distrito de Bento Rodrigues, provocou uma enxurrada de lama que destruiu o local e avançou pelo Rio Doce. Atentar para o acidente de Mariana serve como alerta para a criação de medidas mais eficazes de segurança para mineradoras e para as comunidades que as cercam.

No atual contexto, as empresas não conseguem se posicionar e disputar mercados somente com preços, prazo e qualidade como diferencial. Os clientes estão cada vez mais ambientalmente conscientes, o que potencializa a preocupação com os aspectos socioambientais no meio dos negócios. Dessa forma, é necessário que exista um comprometimento e um planejamento estratégico em prol da comunidade e do meio ambiente.

\begin{abstract}
A crescente preocupação com as questões ambientais e o aumento das restrições ecológicas no mercado internacional têm levado as empresas a desenvolver novas estratégias que permitam o desenvolvimento de produtos inovadores que minimizem os impactos ambientais e não deixem de trazer benefícios econômicos. Além de crescer no mercado produtivo, a preocupação com o ambiente se espalha pela sociedade, pois os impactos da degradação da natureza se multiplicam. (...) Trata-se de um fenômeno global: os consumidores estão mais conscientes, as leis se tornam mais rígidas, a mídia começa a se interessar pela ética empresarial e a educação ambiental passa das escolas (HASHIMOTO e SANTOS, 2006).
\end{abstract}

Desde o rompimento da barragem em Bento Rodrigues, a FAPEMIG (Fundação de Amparo à Pesquisa do Estado de Minas Gerais) tem incentivado pesquisadores a estar mais próximos às demandas das comunidades impactadas pelo incidente, por meio de editais de pesquisa e de mobilização de protagonistas dos setores empresarial (mineração e cadeia produtiva), científico, educacional e governamental, para conduzirem os processos de mudança necessários para uma mineração mais sustentável e inclusiva. Dessa forma, a FAPEMIG acredita que esse projeto, chamado de NOVA MINERAÇÃO, possa ser um meio de construir novos cenários para o setor que é o elo articulador da economia em Minas Gerais e no Brasil.

\title{
5. Design e complexidade
}

Como demonstrado, a gestão e a solução desses problemas complexos não podem ser entendidas como responsabilidade apenas dos atores políticos, sobretudo neste momento, em que os gestores enfrentam uma intensa crise financeira, conforme explica Lacerda (2018). Como afirmam Melo Neto e Froes (2002, p.15):

Intelectuais, políticos, empresários e pesquisadores sociais apontam distorções, culpam o governo, criticam as políticas públicas e identificam gestores e instituições corruptas, ineficientes e ineficazes. Muito se fala e pouco se faz de concreto e efetivo.

Segundo Lacerda (2018), deve-se deixar o "muito falar" e, de modo responsável, praticar ações em prol do bem comum, pois, se assim for feito, se estará plantando no presente um futuro sensato.

O design, no contexto da pós-modernidade, passa a conter outros significados, ainda pouco definidos, que não se relacionam somente aos aspectos materiais e projetuais do objeto, 
mas, sobretudo, ao conjunto da experiência humana construída pelos objetos produzidos (CARA, 2010 p.17).

Para Moraes (2008), uma disciplina como o design, pelo seu caráter holístico, transversal e dinâmico, posiciona-se como alternativa possível na aproximação de uma correta decodificação da realidade contemporânea. Moraes (2008) explica que "a complexidade tende a se caracterizar pela inter-relação recorrente em meio à abundância das informações hoje facilmente disponíveis. De igual forma, ela se molda pela inter-relação, também recorrente, entre empresa, mercado, produto, consumo e cultura".

Cardoso (2012) afirma que a principal contribuição para "equacionar os desafios do nosso mundo complexo é o pensamento sistêmico", pois quanto mais se conhecem o problema e as interações entre as partes do mesmo de forma simultânea, mais se conhece o problema em sua totalidade. Nesse sentido, as ferramentas e os processos de design podem ser utilizados para promover soluções ao mundo complexo atual. Segundo Lacerda (2017), "nesse contexto, o designer é orquestrador, pois compreende as interfaces, as conjunções e identifica pontos de intercessão, articulando as forças atuantes e promovendo soluções integradas para essa complexidade".

No mundo complexo em que insere-se essa situação, é importante repensar o papel do design dentro de todos os contextos, como forma de colaborar e potencializar a geração de melhores soluções. Talvez a principal lição para o design - assimilada na prática dos designers brasileiros nos últimos vinte anos - seja a de que não existem receitas formais capazes de equacionar os desafios da atualidade (Cardoso, 2012). O cenário contemporâneo mostra uma sociedade fluida, com facilidade de acesso à informação e ao conhecimento. $O$ entendimento da complexidade associada ao design pode mudar a compreensão de projetar.

Para Manzini (2008), o design tem um papel específico na transição que o futuro aguarda: oferecer novas soluções a problemas, sejam velhos ou novos, e propor seus cenários como tema em processos de discussão social, colaborando com a construção de visões compartilhadas sobre futuros possíveis e sustentáveis.

\section{Material e Metodologia}

Foi adotada uma abordagem metodológica qualitativa de natureza aplicada com objetivo exploratório e descritivo. Godoy (1995) explica que a pesquisa qualitativa tem alguns aspectos essenciais, em que o ambiente natural é fonte direta de dados e que, "à compreensão ampla do fenômeno que está sendo estudado, considera que todos os dados da realidade são importantes e devem ser examinados". Para Gerhardt et. al (2009), representatividade numérica não é um fator essencial da pesquisa qualitativa, mas sim o aprofundamento da compreensão. Ela é exploratória, pois "tem como objetivo proporcionar maior familiaridade com o problema, com vistas a torná-lo mais explícito ou a construir hipóteses" (GERHARDT et. al, 2009) e é descritiva, "pois pretende descrever os fatos e fenômenos de determinada realidade" (TRIVIÑOS, 1987). Além disso, é de natureza aplicada, pois "objetiva gerar conhecimentos para aplicação prática, dirigidos à solução de problemas específicos. Envolve verdades e interesses locais." (GERHARDT et. al, 2009).

A pesquisa teve início com a análise da bibliografia relativa aos tópicos de design e complexidade; complexidade e mineração. A etapa seguinte é um estudo de caso que tem como foco o entendimento da aplicação do jogo e de como o mesmo pode auxiliar na ideação de problemas para a mineração, processo detalhado no item 7 deste artigo. A coleta dos dados foi 
realizada por meio de fotografias, anotações e observação durante a aplicação do jogo, e a análise das informações coletadas foi feita pela equipe do projeto para elencar melhorias para futuras aplicações e para novos jogos.

\section{Estudo de caso}

A responsabilidade do designer nesse cenário é pesquisar um método produtivo capaz de associar, ao mesmo tempo, o desenvolvimento e avanço empresarial à prosperidade do meio ambiente e dos indivíduos que moram em seu entorno. Além disso, o designer pode intervir como facilitador do processo, gerenciando os atores políticos e não políticos de forma a gerar soluções para esses problemas complexos, que têm afetado a qualidade de vida das comunidades impactadas.

Assim, foi desenvolvido pela equipe do Centro de Estudos em Design e Tecnologia (CEDtec), em 2017, na Universidade do Estado de Minas Gerais (UEMG), um jogo com a proposta de facilitar a troca de conteúdos e experiências entre os jogadores, com o intuito de idear projetos mais eficientes no contexto fluido e dinâmico do mundo hoje, além de possibilitar aos participantes a vivência da aplicação de conceitos do design como propositor de soluções para problemas complexos.

Os objetivos do jogo são introduzir e discutir ferramentas do design para solucionar problemas complexos usando o contexto da mineração, seus desafios e potencialidades, a fim de promover a compreensão da responsabilidade de cada indivíduo no processo. A atividade ainda permite a geração de ideias em grupos, com o intuito de construir soluções coletivas para minimizar os problemas apresentados. As ideias resultantes da ação, posteriormente, devem ser analisadas e priorizadas para que aconteça a implementação e medição de seu impacto.

O jogo é dividido em cartas-situação, cartas-bônus e cartas-barreira. Cartas-situação são descrições de problemas que costumam ocorrer em cidades onde já acontece a mineração ou onde uma nova companhia mineradora vai se instalar. As situações são:

1. Você está em Mariana, depois do desastre que aconteceu em Dezembro de 2015, e muito pouco foi feito, como mudar esse cenário?

2. Existe uma barragem nova, construída, mas o prefeito não negociou nenhum benefício para a comunidade com a mineradora e a empresa não ofereceu nenhuma contrapartida para a comunidade.

3. O minério está acabando e as empresas devem ir embora em 5 anos, deixando apenas o passivo (pity e poluição) para trás, não existe nenhum acordo até o momento.

4. A mineradora já foi embora, a cidade está falida, a população diminuindo e um pity gigante como herança.

5. Foi descoberto um veio de minério muito rico no município e uma mineradora quer se instalar na cidade. 
Figura 1 - Cartas-situação
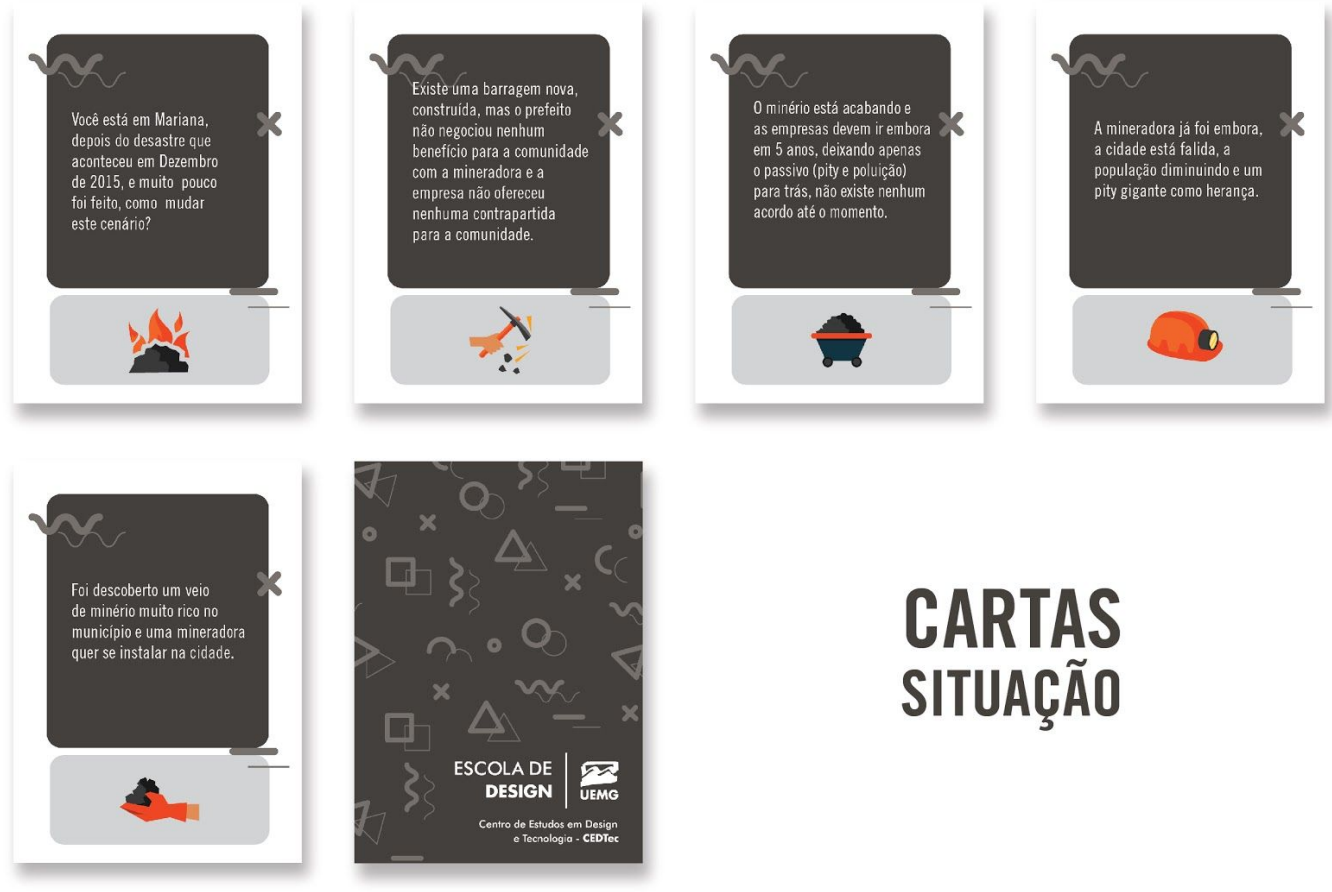

\section{CARTAS SITUAÇÃ̃o}

Fonte: Elaborada pelas autoras, 2017

As cartas-bônus ilustram benefícios que a equipe poderia ter para solucionar o problema que foi apresentado na carta-situação.

1. Linha de financiamento com juros altos, mas pré-aprovado para pagamento em 10 anos;

2. Crowdfunding;

3. Financiamento do BNDES, com juros subsidiados, para pagar em 20 anos;

4. Emenda parlamentar para liberação de recursos para o município, para serem aplicados em projetos relacionados a sustentabilidade;

5. Parceria com universidades e centros de pesquisa;

6. Apoio das mineradoras presentes no município;

7. Apoio dos moradores e associações;

8. Apoio da prefeitura;

9. Apoio do governo do estado;

10. Equipe pluridisciplinar disponível. 


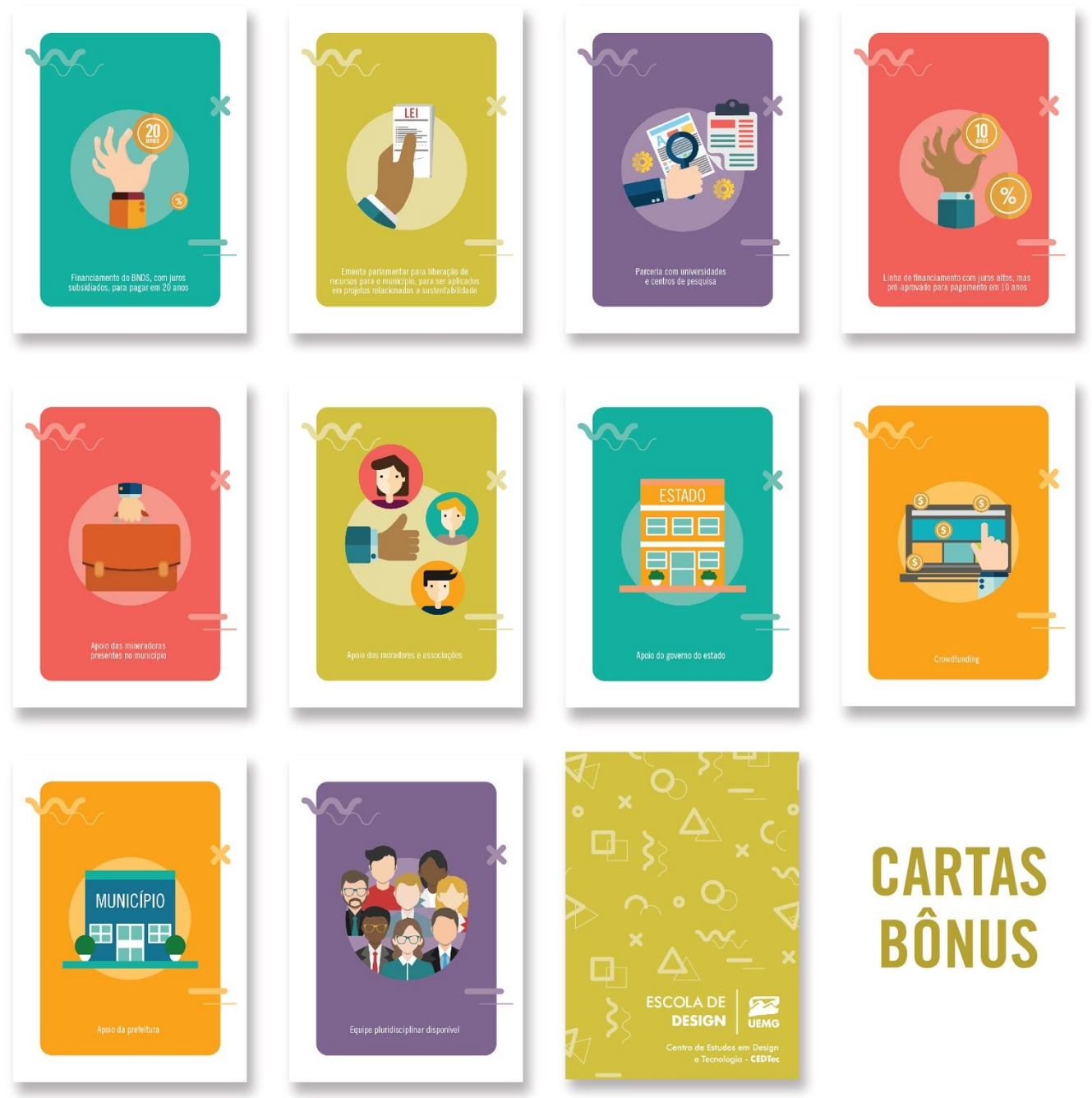

Fonte: Elaborada pelas autoras, 2017

As cartas-barreira demonstram possíveis situações complicadas que podem surgir ao longo de um projeto, e a equipe teria que gerar ideias para resolver e seguir com a solução do problema da carta-situação. As cartas-barreira são:

1. Prefeito corrupto;

2. Maioria da população não cooperativa, clima de desconfiança;

3. Falta de diálogo entre os diferentes grupos;

4. Imposição de novo modo de vida pela empresa;

5. Prefeitura falida;

6. Conflito entre as mineradoras presentes; 
7. Conflito entre as empresas que já reaproveitam parte dos rejeitos;

8. Conflito com as empresas de soluções similares no mercado;

9. Escândalo de corrupção na mineradora;

10. Novo desastre ambiental.

Figura 3 - Cartas-barreira

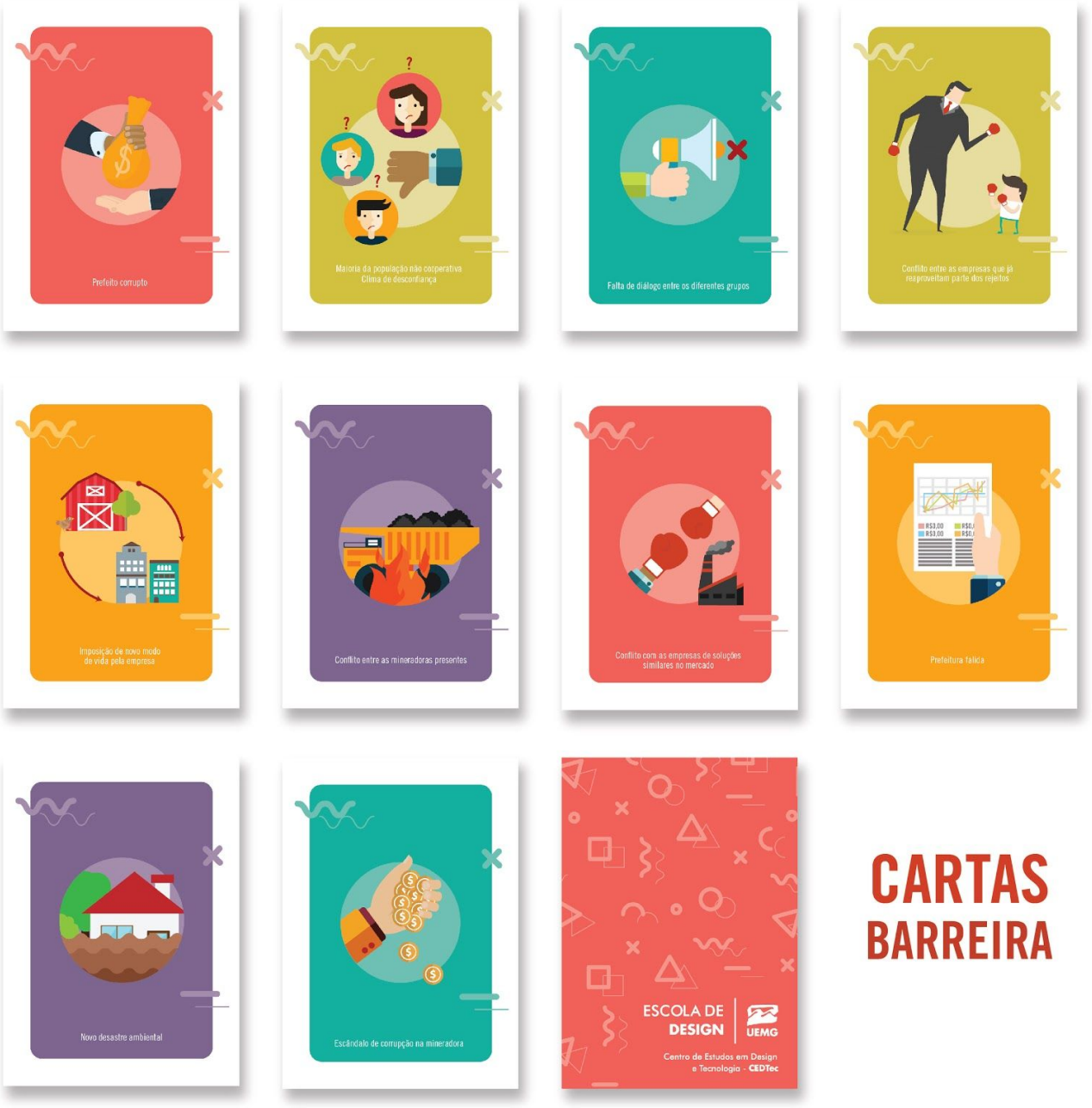

Fonte: Elaborada pelas autoras, 2017

Para aplicação do jogo, foi elaborada uma oficina e foram convidados os alunos da pós-graduação da UEMG - mulheres e homens com diferentes formações, entre elas: design, arquitetura, administração e direito, com idades entre 26 e 35 anos. A estrutura da oficina se divide em quatro etapas:

Primeira Etapa: Apresentação da equipe, da proposta e das motivações que levaram a equipe a montar a oficina e desenvolver esse jogo com diversos públicos-alvo.

Segunda Etapa: Contextualização dos benefícios e problemas gerados pela mineração. Introdução e discussão acerca de ferramentas do design utilizadas na geração de ideias para solucionar problemas complexos. 
Terceira Etapa: Explicação do funcionamento do jogo e dos resultados esperados, seguida pela divisão dos grupos de trabalho e sorteio das cartas. Cada grupo prossegue retirando uma carta-situação e sorteando no dado a quantidade de cartas-bônus e barreira que vai receber.

Quarta Etapa: Análise das soluções geradas e possibilidades de implementação, além do compartilhamento das soluções geradas para os demais grupos.

Figura 4 - Oficina de ideação na UEMG
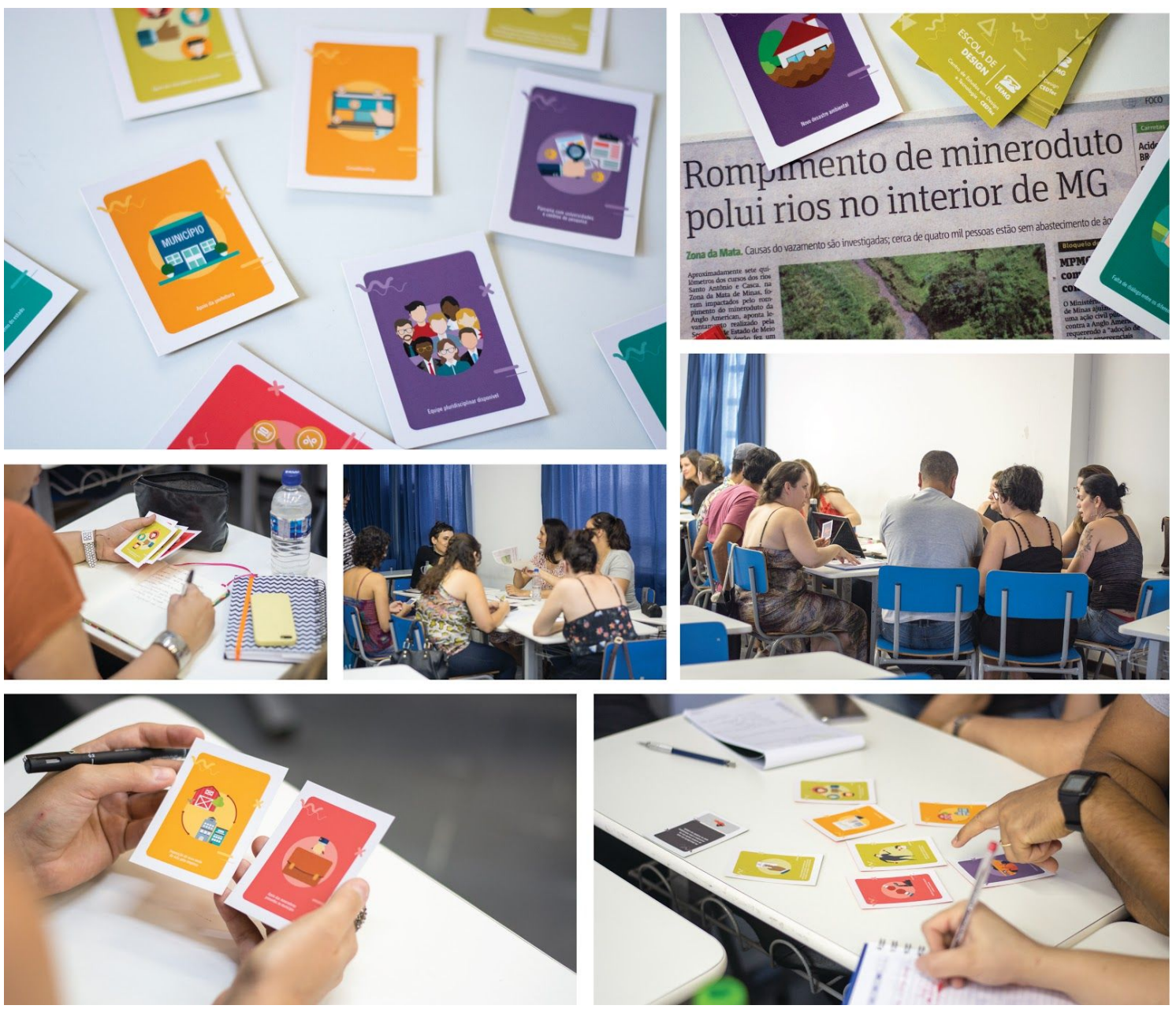

Fonte: Fotografias tiradas durante o workshop, 2017

Após a explicação do jogo, divisão dos grupos e sorteio das cartas, foram dados 10 minutos a cada grupo para ler as cartas que tinha recebido, realizar uma conversa entre os integrantes e sanar possíveis dúvidas sobre cada carta. Então, eles tiveram 4 horas para desenvolver ideias. Durante esse período, a equipe do projeto auxiliou os grupos à medida que as dúvidas iam surgindo, dando mais informações sobre a mineração, a comunidade, as empresas mineradoras e o próprio jogo. Após duas horas de o tempo ter sido iniciado, houve um novo sorteio de cartas bônus e de cartas-barreira, com o intuito de mostrar que, durante o processo de geração e implementação de soluções, podem surgir novas variáveis que ajudam ou atrapalham a execução do projeto. 
Os principais desafios enfrentados foram: inserir os jogadores na realidade da mineração, pela distância que eles tinham dessa atividade, considerando que ela não faz parte da realidade dos mesmos; a dificuldade de saber se uma ideia era viável ou não, foi motivo de discussão de alguns grupos, porém, a viabilidade da solução não é um ponto que precisa ser discutido nesse momento, pois é um limitador na geração de ideias. Uma das participantes morava na região de Ipatinga - Minas Gerais e deu um relato sobre como o comércio local só funciona por causa do fluxo de pessoas que as grandes empresas geram e que, quando essas empresas encerram as atividades, há um prejuízo para a cidade toda. Esse relato ajudou a ilustrar a situação das cidades que têm como principal fonte de renda as mineradoras e o que acontece quando o minério acaba, que é uma das cartas-situação apresentadas pelo jogo.

Ao final, os grupos tiveram 10 minutos de explanação para toda a turma. Durante os relatos, os grupos apresentaram soluções de curto, médio e longo prazo envolvendo a comunidade, o setor público e o setor privado. Uma das ideias foi que as empresas mineradoras criassem escolas técnicas nas comunidades, para que as pessoas fossem capacitadas e tivessem outras possibilidades de trabalho, além da mineração. Uma outra foi criar uma poupança em que a empresa mineradora tivesse que fazer um depósito mensal referente ao tempo e à quantidade de minério que retirou na cidade, para que, quando encerrasse as atividades, a cidade pudesse usar esse dinheiro para não falir.

Alguns participantes propuseram melhorias ao jogo, como mudar cartas que possam ter uma interpretação similar, criar uma manual de uso e colocar no verso das cartas um texto detalhando como aquela carta pode ajudar ou atrapalhar o projeto.

Os participantes relataram uma tomada de consciência sobre a importância do tema abordado e que, por meio da metodologia desenvolvida, puderam perceber como o design pode ser um mediador na proposição de soluções para problemas complexos no contexto atual. Além disso, os participantes relataram a importância da participação de todos os envolvidos no problema (comunidade, moradores, prefeituras, governos, universidades e outras instituições e empresas) em processos de codesign para gerar e implementar as possíveis soluções.

\section{Considerações finais}

Percebe-se que existe um movimento de transição do modelo de pensamento mecanicista para um modelo de pensamento complexo, e o design deve acompanhar essa evolução, pois é capaz de permear as mais diversas áreas de conhecimento, podendo atuar transdisciplinarmente associado a outros profissionais, oferecendo uma nova abordagem para problemas complexos. Como afirma Melo Filho (2009), "[...] sua ação multidisciplinar, com efetivas possibilidades de prática comum a duas ou mais disciplinas ou ramos de conhecimento, [...] pode atuar em sinergia, possibilitando a ênfase em um objetivo comum". Ainda que o designer não tenha todas as habilidades para solucionar problemas específicos, percebe-se que o pensamento holístico, analisando criticamente e com um novo olhar para o problema, pode colaborar para soluções criativas e eficazes.

Brincar pode ser um instrumento efetivo no processo de criação e inovação, à medida que encoraja espontaneidade e experimentações (CHARALAMPOS e RONSONS, 2006), o que foi colocado em prática durante a oficina proposta. A distribuição das cartas-barreira e bônus por meio da "sorte" e a expertise de cada membro do grupo levaram os envolvidos a pensar em soluções com olhares completamente singulares para cada tipo de situação enfrentada. A dinâmica se mostrou efetiva e importante, pois a mente costuma trabalhar no sentido oposto ao 
novo, indo ao encontro do padrão e do hábito, tendendo a repetir o processo, em vez de cogitar diferentes modos de executar uma ação (GANEM, 2016), e isso foi rompido por meio do jogo, o que possibilitou a geração de soluções criativas e aplicáveis.

O design oferece ferramentas e processos que podem contribuir para que projetos sejam pensados de maneira cada vez mais integrada entre sociedade, economia e meio ambiente e para entender e projetar para sistemas complexos, que podem ser pensados além do escopo comercial - das relações de compra e venda. O design tem competências que podem contribuir para uma melhor compreensão da complexidade. 


\section{REFERÊNCIAS}

AZEVEDO, W. O que é design? Editora Brasiliense, Coleção primeiros passos, 2008

BOMFIM, G. A.. Idéias e formas na história do design: uma investigação estética. Campina Grande: UFPB, 1995.

CARA, M.. Do Desenho Industrial ao Design no Brasil. Editora Blucher. São Paulo, SP: 2010.

CARDOSO, Rafael. Uma introdução a história do design. Editora Blucher. São Paulo, SP. 2008.

Design para um mundo complexo. Editora Cosac Naify. São Paulo, SP. 2012

CHARALAMPOS, Mainemelles; RONSONS, Sarah. Play and Creativity. 2006.

FLUSSER, V.. O mundo codificado. Por uma filosofia do design e da comunicação. Editora Cosac Naify. São Paulo, SP. 2007.

GANEM Márcia. Design Dialógico: Gestão criativa, inovação e tradição. São Paulo: Estação das Letras e Cores, 2016.

HASHIMOTO, Vivian; SANTOS, Maria Cecília Loschiavo dos. Design com consciência ambiental: projeto de mobiliário pré-escolar. 2006. Disponível na internet por HTTP em:< http://www.fau.usp.br/disciplinas/tfg/tfg_online/tr/062/a076.html> Acesso: 03 abril 2018.

MANZINI, E. Design para a inovação social e sustentabilidade. Cadernos do Grupo de Altos Estudos, Programa de Engenharia de Produção da Coppe/UFRJ, Rio de Janeiro, vol. I 2008.

MATOZA, B. B.. Gestão do design: Usando o design para construir valor de marca e inovação corporativa. Porto Alegre: Bookman, 2011.

MORIN, E. Introdução ao pensamento complexo. Porto Alegre: Sulina; 2012

MORIN E. Introdução ao pensamento complexo. Porto Alegre: Sulina; 2006

MORITZ, S. Service Design: Practical access to an evolving field. Londres, 2005

MORAES, D. Metaprojeto, o design do design. São Paulo: Edgard Blucher, 2010.

MORAES, D. Design e transversalidade. Belo Horizonte : Santa Clara : Centro de Estudos Teoria, Cultura e Pesquisa em Design. UEMG, 2008.

NUNES, J. M.; INFANTE Maria. Pesquisa-ação: uma metodologia de consultoria. Disponível na internet por HTTP em:<goo.gl/okTC8s> Acesso: 03 março 2018.

PAPANEK, Victor. Arquitetura e design: ecologia e ética. Lisboa: Edições 70, 1995.

PINE, B., GILMORE, J.. Welcome to the experience economy. Harvard Business Review, Julho-agosto, 1998.

POTTER, N.. What is a Designer: Things, Places, Messages. Hyphen, 2002.

RITTEL, H. W. J.; WEBBER, M. M. Dilemmas in a general theory of planning. Policy sciences, v. 4 n. 2, p. 155-169. 1973.

THACKARA, J.. In the bubble: designing in a complex world. United States. 336 p. 2005. 
.Plano B : o design e as alternativas viáveis em um mundo complexo. São Paulo: Saraiva , 2008.

TORRES, J. J. M.. Teoria da complexidade: uma nova visão de mundo para a estratégia. Rev. de Inv. Educ. v.2 n.2 La paz, 2009.

VIANNA, Maurício et.al. Design Thinking: inovação em negócios. Rio de Janeiro: 2012.

VASSÃO, A. C. Metadesign: ferramentas, estratégias e ética para a complexidade. São Paulo, SP: Blucher, 2010. 